\title{
Case Report: Cutaneous Squamous Cell Carcinoma Arising From the Ulcer of the Lesions of Dupuytren's Disease on the Palm
}

\author{
Qingmiao Sun ${ }^{1}$, Bin $\mathrm{Fu}^{2}$, Sheng $\mathrm{Li}^{1}$, Hong Fang ${ }^{1 *}$ and Jianjun Qiao ${ }^{1 *}$ \\ ${ }^{1}$ Department of Dermatology, The First Affiliated Hospital, Zhejiang University School of Medicine, Hangzhou, China, \\ 2 Department of Infectious Diseases, Hangzhou Hospital of Traditional Chinese Medicine, Hangzhou, China
}

OPEN ACCESS

Edited by:

Todd Ridky,

University of Pennsylvania,

United States

Reviewed by:

Paul Haun,

University of Pennsylvania,

United States

Ashley M. Holder,

University of Alabama at Birmingham,

United States

loana Cosgarea,

Newcastle University, United Kingdom

${ }^{*}$ Correspondence:

Hong Fang

fanghongzy@zju.edu.cn

Jianjun Qiao

qiaojianjun@zju.edu.cn

Specialty section:

This article was submitted to

Skin Cancer,

a section of the journal

Frontiers in Oncology

Received: 06 December 2020

Accepted: 08 March 2021

Published: 25 March 2021

Citation:

Sun Q, Fu B, Li S, Fang H and Qiao J (2021) Cutaneous Squamous Cell

Carcinoma Arising From the Ulcer of the Lesions of Dupuytren's

Disease on the Palm.

Front. Oncol. 11:638395.

doi: 10.3389/fonc.2021.638395
Dupuytren's disease is a benign fibromatosis that mainly involves the fascia of the palm and digits. The relationship between Dupuytren's disease and the evolution of cutaneous squamous cell carcinoma is still unclear. Here we report the case of a 52-year-old female with squamous cell carcinoma arising from the ulcer of the lesions of Dupuytren's disease on the left palm. To our knowledge, this is the first reported case in the English literature of squamous cell carcinoma on the palm of someone with Dupuytren's disease.

Keywords: Dupuytren's disease, squamous cell carcinoma, palm, skin cancer, surgical excision

\section{INTRODUCTION}

Dupuytren's disease (DD) is a connective tissue disorder of the hand characterized by excessive fibrosis of the palmar fascia. DD results in finger contracture and disability (1). It is usually progressive, irreversible, symmetrical, and with a late-onset. The 4th and 5th digits are most often affected. Prevalence rates range from $0.2 \%$ to $56 \%$ (2) and the exact pathogenesis of DD remains unclear.

Squamous cell carcinoma (SCC) is the most common skin cancer of the hand. However, SCC associated with DD has been rarely reported. Haslik et al. (3) reported a case of SCC in the presence of DD in the language of German. Alberico et al. (4) reported another case of SCC in the presence of Ledderhose disease. Ledderhose disease is considered to share a spectrum with $\mathrm{DD}$ and $10 \%$ of the patients of DD can be found with Ledderhose disease (5). To our knowledge, this is the first case in the English literature of SCC on the palm of a patients with DD.

\section{CASE REPORT}

Written informed consent was obtained from the patient for the publication of any potentially identifiable images or data included in this article. The report was approved by the ethics committee of the First Affiliated Hospital, Zhejiang University School of Medicine (Approved number: IIT2020-664).

A 52-year-old female with long standing severe DD affecting 3rd to 5th digits of both hands presented to our department of dermatology with a 1-year history of a painful non-healing slowly 
enlarging ulcerated nodule on her left palm. The patient did not recall any personal or family history of skin cancer, diabetes mellitus, epilepsy and genetic disease. She also denied history of smoking, alcohol consumption, heavy labor, trauma and immunodeficiency. Physical examination showed a $2.0 \times 1.0 \mathrm{~cm}$ red ulcer on the flexor side of the 5 th metacarpophalangeal joint of the left hand (Figures 1A, B). There was flexion contracture of the 3rd to 5 th fingers of both hands, and the 5th finger of the right hand was fused with the palm.

No obviously enlarged lymph nodes were evident in the bilateral axilla using ultrasonography. A cutaneous biopsy specimen taken from the edge of the ulcer showed hyperkeratosis of the epidermis, with infiltration of atypical squamatous cells into the dermis with horn pearls. No evidence of fungal or mycobacterium infection was found. Immunohistochemistry showed the atypical squamous cells were positive for pan cytokeratin and negative for vimentin. Well differentiated SCC was diagnosed (Figure 2).

An axillary lymph node biopsy did not reveal any neoplastic cells. The patient requested an amputation of her left hand at the wrist. The patient has been followed-up for 8 years and has remained free of recurrence of the SCC (Figure 3).

\section{DISCUSSION}

DD is considered a benign but debilitating disease due to the decreased range of motion and grip strength. Dysregulation of certain genes may affect the growth characteristics of fibroblasts in palmar aponeurosis, leading to gradual differentiation into myofibroblasts and excessive production of type III collagen (6). Infiltrative growth, proliferation, lack of apoptosis, and a tendency to relapse are the characteristics of DD fibroblasts. One study showed that the incidence of fibrosarcoma and 2malignant fibrous histiocytoma may increase in DD patients (7).
However, no correlation has been established between DD and the formation of skin malignancies. Non-melanoma skin cancers (NMSCs) tend to occur less frequently among female DD patients (8). However, it is believed that the prevalence of skin tumors may be underestimated and not adequately documented. A recent retrospective study of $181 \mathrm{DD}$ patients showed that the risk of NMSC in DD patients was twice that of the controls (9). Thus, the relationship between DD and skin cancers remains unclear.

Cutaneous SCC is the most common primary malignancy of the hand. It has an increasing annual incidence, accounting for 20 to $30 \%$ of cutaneous malignancies $(10,11)$ and 58 to $90 \%$ of all hand tumors $(12,13)$. It is almost always located on the dorsum of the hand, with very rare occurrence on the palm (14). Only a few case reports of SCC on the palm have been published (15, 16). The ulcer on the palm of our patient was finally diagnosed with cutaneous SCC. However, it still needs to be differentiated from trauma, pyoderma, fungal or mycobacterium infection.

SCC in the presence of DD is rarely reported as well as in the presence of Ledderhose disease, Garrod knuckle pads, and Peyronie's disease which share common predisposing factors, comorbidities, pathophysiology, and evolution with $\operatorname{DD}(5,9)$. The two reported cases are mentioned above. To our knowledge, there are no reports of SCC in the presence of Garrod knuckle pads and Peyronie's disease, and this is the first case in the English literature of SCC on the palm of a patients with DD. It is postulated that chronic inflammation/wound and scarring in DD may be the cause of SCC.

Surgical excision is one of the main treatments for cutaneous SCC. Surgery requires consideration of recurrence rate, function preservation, patient expectation, and potential adverse reaction $(17,18)$. The current literature on the surgical treatment of cutaneous SCC is conflicting, with no conclusive results on the effectiveness of various prognostic factors and surgical approaches for primary tumors (19). According to the guidelines of care for
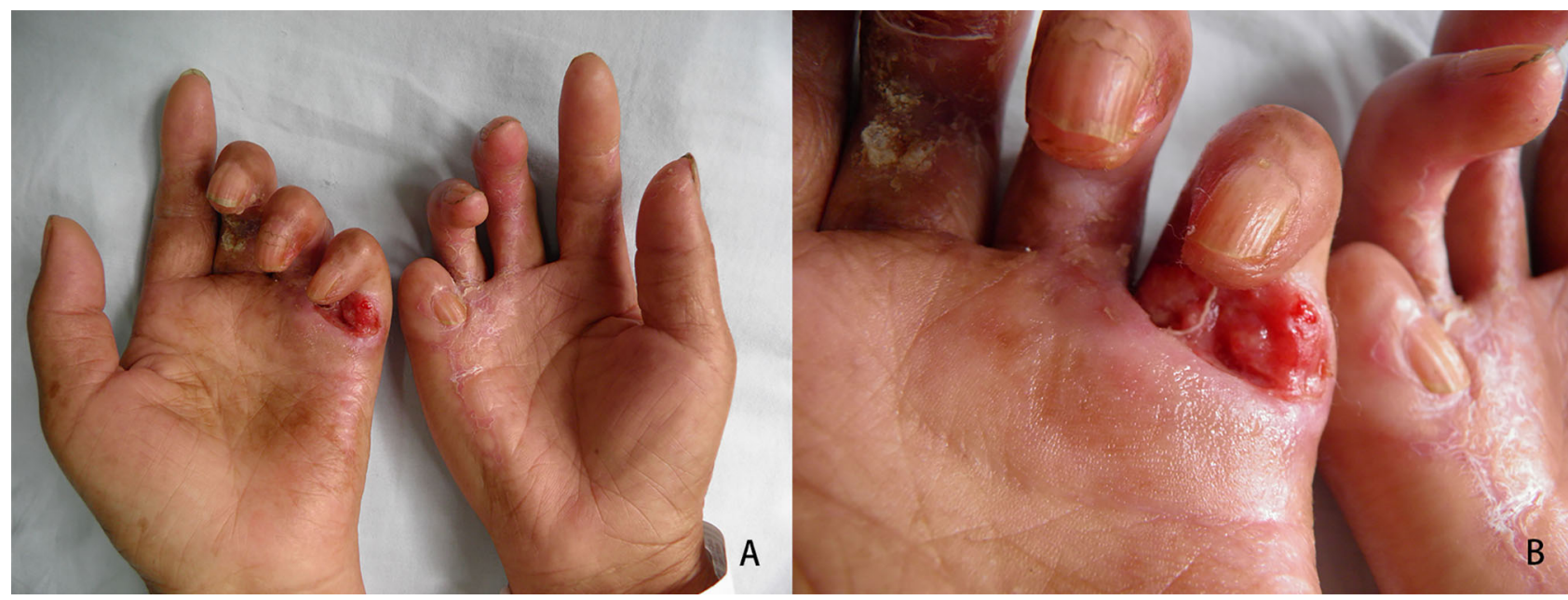

FIGURE 1 | Clinical features of the hand lesions. (A, B) Contracture deformity of both hands was evident, and an ulcer was detected on the flexor side of the 5 th metacarpophalangeal joint of the left hand. 

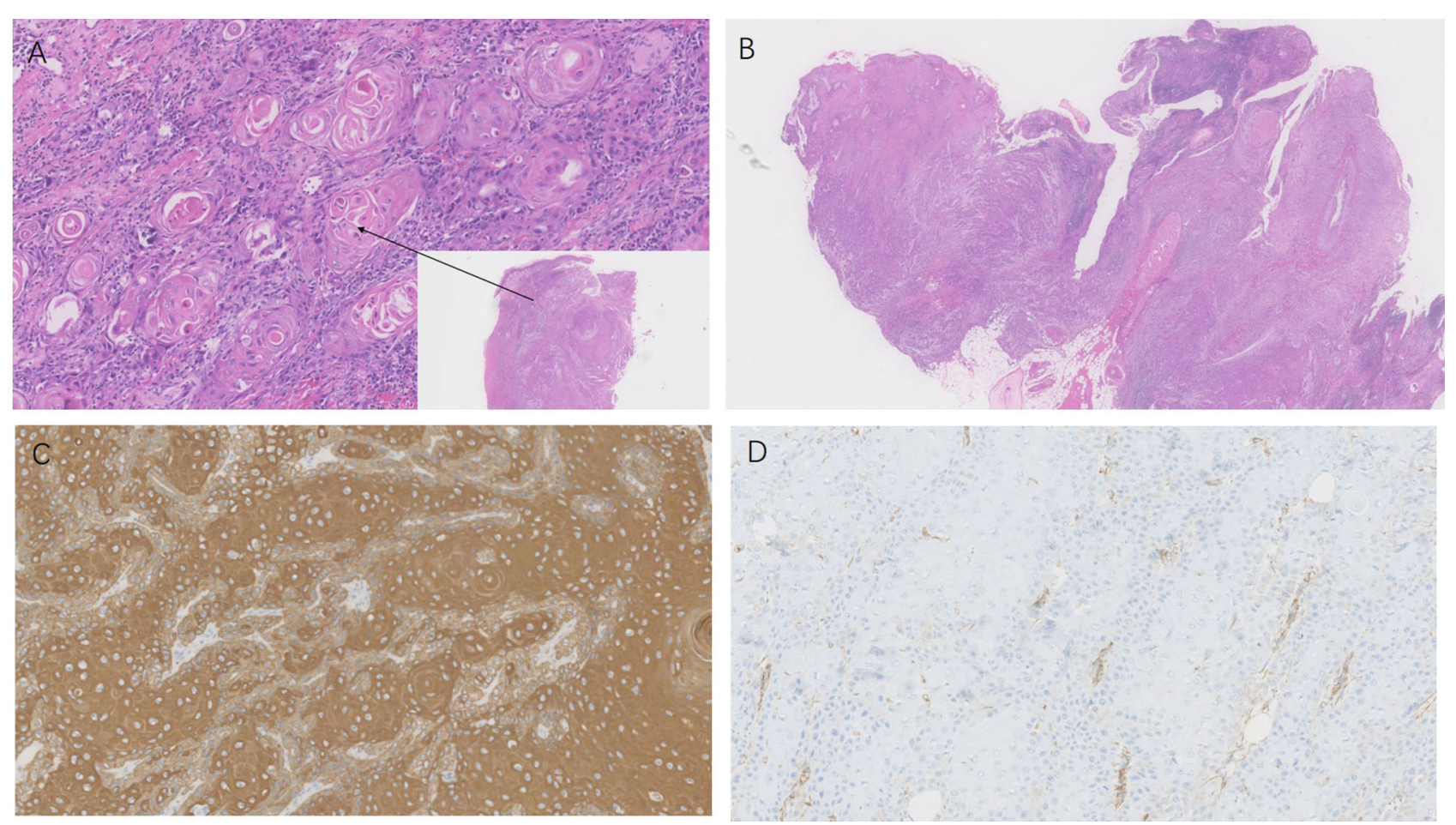

FIGURE 2 | Histopathology of the hand lesion. HE staining of the tissue (panel A was from the edge of the ulcer, panel $\mathbf{B}$ was from the ulcer) revealed atypical squamous cell proliferation and horn pearls in the dermis (H\&Ex100, $\times 10)$. Immunohistochemical staining of the biopsy specimen showed (C, D) the squamous cells were positive for pan cytokeratin and negative for vimentin $(\times 100)$.

\section{Dupuytren's disease ulcer follow-up after surgery}
20 years
1 year
8 years

FIGURE 3 | Timeline of the disease's development.

the management of cutaneous SCC by the American Academy of Dermatology (20), for low-risk primary cutaneous SCC, standard excision is recommended with a margin width of 4 to $6 \mathrm{~mm}$ to a depth of the middle layer of subcutaneous adipose tissue by histologic margin assessment. For high-risk primary cutaneous SCC, Mohs micrographic surgery is recommended. Similar to this guidelines, for high risk cutaneous SCC that has not spread to lymph nodes, Mohs surgery or resection with complete circumferential peripheral and deep margin assessment or standard surgical excision is recommended by National Comprehensive Cancer Network (NCCN) guidelines (21). Few studies have focused on the outcomes of SCC of the hand treated by surgical excision, and the use of amputation as a treatment for such SCC is controversial (15). In a retrospective study of 273 patients with SCC of the hand, the death rate from metastasis was $21 \%$ with amputation, compared with $7 \%$ with radiotherapy alone (22). In the present case, the patient suffered from DD for 20 years with severe hand dysfunction and presented with a 1-year history of non-healing enlarging ulcerated nodule that was confirmed as SCC. According to the risk factors of NCCN guidelines (21), the tumor occurred in an ulcer site on the hand with $20 \mathrm{~mm}$ in size was of high-risk, and an axillary lymph node biopsy was required. Although the axillary lymph node biopsy was negative, the patient declined to receive Mohs surgery and selected amputation at the left wrist because of the serious functional impairment of her left hand and worried about recurrence.

In summary, $\mathrm{DD}$ is a common benign fibromatosis mainly involving the fascia of the palm and digits. However, SCC in the palm accompanying the disease has not been previously described in the English literature. The incidence of SCC in DD is unclear. Further attention should be given to the incidence, and routine dermatological examinations are necessary for such patients. 


\section{DATA AVAILABILITY STATEMENT}

The original contributions presented in the study are included in the article/supplementary material. Further inquiries can be directed to the corresponding authors.

\section{ETHICS STATEMENT}

Written informed consent was obtained from the patient for the publication of any potentially identifiable images or data included in this article.

\section{REFERENCES}

1. Karkampouna S, Kreulen M, Obdeijn MC, Kloen P, Dorjée AL, Rivellese F, et al. Connective Tissue Degeneration: Mechanisms of Palmar Fascia Degeneration (Dupuytren's Disease). Curr Mol Biol Rep (2016) 2:133-40. doi: 10.1007/s40610-016-0045-3

2. Hindocha S, McGrouther DA, Bayat A. Epidemiological evaluation of Dupuytren's disease incidence and prevalence rates in relation to etiology. Handbook (NY) (2009) 4:256-69. doi: 10.1007/s11552-008-9160-9

3. Haslik W, Schrögendorfer KF, Sulzbacher I, Frey M. Squamous cell carcinoma in Dupuytren's disease-a case report. Handchir Mikrochir Plast Chir (2011) 43:54-6. doi: 10.1055/s-0030-1268480

4. Motolese A, Mola F, Cherubino M, Giaccone M, Pellegatta I, Valdatta L. Squamous cee carcinoma and ledderhose disease: a case report. Int J Low Extrem Wounds (2013) 12:297-300. doi: 10.1177/1534734613502044

5. Bogdanov I, Rowland-Payne C. Dupuytren contracture as a sign of systemic disease. Clin Dermatol (2019) 37:675-8. doi: 10.1016/j.clindermatol.2019.07.027

6. Kloen P. New insights in the development of Dupuytren's contracture: A review. Br J Plast Surg (1999) 52:629-35. doi: 10.1054/bjps.1999.3187

7. Wilbrand S, Ekbom A, Gerdin B. Dupuytren contracture and sarcoma. J Handb Surg Br (2002) 27:50-2. doi: 10.1054/jhsb.2001.0652

8. Zyluk A, Paszkowska-Szczur K, Gupta S, Scott RJ, Lubiński J, Dębniak T. Dupuytren's disease and the risk of malignant neoplasms. Hered Cancer Clin Pract (2014) 12:6. doi: 10.1186/1897-4287-12-6

9. Bogdanov I, Rowland Payne C. Dupuytren contracture as a sign of systemic disease. Clin Dermatol (2019) 37:675-8. doi: 10.1016/j.clindermatol

10. Madan V, Lear JT, Szeimies RM. Non-melanoma skin cancer. Lancet (2010) 375:673-85. doi: 10.1016/S0140-6736(09)61196-X

11. Stratigos A, Garbe C, Lebbe C, Malvehy J, Marmol V, Pehamberger H, et al. Diagnosis and treatment of invasive squamous cell carcinoma of the skin: European consensus-based interdisciplinary guideline. Eur J Cancer (2015) 51:1989-2007. doi: 10.1016/j.ejca.2015.06.110

12. Askari M, Kakar S, Moran SL. Squamous cell carcinoma of the hand: a 20-year review. J Handb Surg Am (2013) 38:2124-33. doi: 10.1016/j.jhsa

13. Martin DE, English JC III, Goitz RJ. Squamous cell carcinoma of the hand. J Handb Surg Am (2011) 36:1377-81. doi: 10.1016/j.jhsa.2011.03.018

\section{AUTHOR CONTRIBUTIONS}

All authors contributed to the article and approved the submitted version.

\section{FUNDING}

This work was supported by the Zhejiang Medical and Health Science and Technology Project (2015KYA092).

14. Terkonda SP, Perdikis G. Non-melanotic skin tumors of the upper extremity. Handb Clin (2004) 20:293-301. doi: 10.1016/j.hcl.2004.03.018

15. Onuigbo WI, Njeze GE. Squamous Cell Carcinoma of the Palm in Nigeria. Niger J Surg (2016) 22:123-6. doi: 10.4103/1117-6806.169872

16. González-Sosa D, Brea-García B, Couto-González I, Taboada-Suárez A. Moderately differentiated squamous cell carcinoma of the palm: an extremely infrequent tumour. BMJ Case Rep (2014) 2014:1-3. doi: 10.1136/bcr-2014-206350

17. Yun MJ, Park JU, Kown ST. Surgical Options for Malignant Skin Tumors of the Hand. Arch Plast Surg (2013) 40:238-43. doi: 10.5999/aps.2013.40.3.238

18. Chren MM, Sahay AP, Bertenthal DS, Sen S, Landefeld CS. Quality-of-life outcomes of treatments for cutaneous basal cell carcinoma and squamous cell carcinoma. J Invest Dermatol (2007) 127:1351-7. doi: 10.1038/sj

19. Breuninger H, Eigentler T, Häfner HM, Leiter U. Local surgical treatment of cutaneous squamous cell carcinoma: deficits and controversies in the literature. J Dtsch Dermatol Ges (2019) 17:999-1004. doi: 10.1111/ddg

20. Work Group, Invited Reviewers, Kim JYS, Kozlow JH, Mittal B, Moyer J, Olenecki T, Rodgers P, et al. Guidelines of care for the management of cutaneous squamous cell carcinoma. J Am Acad Dermatol (2018) 78:560-78. doi: 10.1016/j.jaad.2017.10.007

21. National Comprehensive Cancer Network and Squamous Cell Skin Cancer. NCCN Guidelines Version 1.2020, in NCCN Clinical Practice Guidelines in Oncology. (2019). Available at: https://www.nccn.org/professionals/physician gls/default.aspx\#sites.

22. Rayner CR. The results of treatment of two hundred and seventy-three carcinomas of the hand. Hand (1981) 13:183-6. doi: 10.1016/s0072-968x(81)80061-7

Conflict of Interest: The authors declare that the research was conducted in the absence of any commercial or financial relationships that could be construed as a potential conflict of interest.

Copyright (C) 2021 Sun, Fu, Li, Fang and Qiao. This is an open-access article distributed under the terms of the Creative Commons Attribution License (CC BY). The use, distribution or reproduction in other forums is permitted, provided the original author(s) and the copyright owner(s) are credited and that the original publication in this journal is cited, in accordance with accepted academic practice. No use, distribution or reproduction is permitted which does not comply with these terms. 